\title{
Larval Gnathostoma hispidum detected in the red banded odd-tooth snake, Dinodon rufozonatum rufozonatum, from China
}

\author{
Shin-Hyeong $\mathrm{CHO}^{1)}$, Tong-Soo $\mathrm{KIM}^{1)}$, Yoon $\mathrm{KONG}^{2)}$, Byoung-Kuk NA ${ }^{3)}$ and Woon-Mok SOHN ${ }^{3) *}$ \\ ${ }^{1)}$ Department of Malaria and Parasitic Diseases, National Institute of Health, Seoul 122-701, \\ ${ }^{2)}$ Department of Molecular Parasitology, College of Medicine, Sungkyunkwan University, Suwon 440-746, \\ ${ }^{3)}$ Department of Parasitology and Institute of Health Sciences, Gyeongsang National University College of Medicine, \\ Jinju 660-751, Korea
}

\begin{abstract}
A total of 205 larval gnathostomes were collected from 18 (22.5\%) of 80 red banded odd-tooth snakes, Dinodon rufozonatum rufozonatum, which had been smuggled from China and confiscated at Customs in Busan, Republic of Korea. In order to identify the species, some of the larvae were observed by a light microscope and a scanning electron microscope (SEM). The larvae were $2.18 \times 0.29 \mathrm{~mm}$ in average size, and had a pair of lips at the anterior end, a muscular esophagus, 2 pairs of cervical sacs, and brownish intestines. The head bulb was characteristically equipped with 4 rows of hooklets; the average number of hooklets in each respective row was 38.6, 40.5, 41.5, and 43.7. In SEM views, the mouth evidenced a pair of lateral lips of equal size in a half-moon shape. Each lip featured a couple of labial papillae and a small amphid located between the 2 papillae. The hooklets on the head bulb had single-pointed, posteriorly-curved tips. The cuticular spines were larger and more densely distributed on the anterior part of the body, and decreased gradually in size and number toward the posterior body. On the basis of these morphological characteristics, the larvae were identified as the third stage larvae of Gnathostoma hispidum.
\end{abstract}

Key words: Gnathostoma hispidum, red banded odd-tooth snakes, Dinodon rufozonatum rufozonatum, scanning electron microscopy (SEM)

\section{INTRODUCTION}

Gnathostoma species are clinically important nematodes, and have been recognized as the causative agents of larva migrans. Although approximately 20 species have been identified in various localities of the

- Received 23 April 2007, accepted after revision 24 July 2007

- This work was supported by an Anti-Communicable Diseases Control Program of the National Institute of Health (NIH 348-6111-215), Ministry of Health and Welfare, Republic of Korea.

*Corresponding author (e-mail: wmsohn@gsnu.ac.kr) world, only a half of them, i.e., G. spinigerum, G. hispidum, G. turgidum, G. doloresi, G. nipponicum, G. americanum, G. procyonis, G. miyazakii, G. malaysiae, and $G$. vietnamicum were demonstrated to be valid species (Miyazaki, 1991). Among them, 4 species, i.e., G. spinigerum, G. hispidum, G. nipponicum, and G. dorolesi have been detected from human infections (Morishita, 1924; Ando et al., 1988; Nawa et al., 1989). In the case of G. hispidum, it has been reported that a significant number of Japanese individuals was infected through consumption of raw flesh of loaches imported from China (Morita et al., 1984; Demitsu and Aizawa, 1985; Araki, 1986). 
Table 1. Length and weight of snakes examined in this study

\begin{tabular}{|c|c|c|c|c|c|}
\hline \multirow{2}{*}{ Species of snake } & \multirow{2}{*}{$\begin{array}{l}\text { No. of snakes } \\
\text { examined }\end{array}$} & \multicolumn{2}{|c|}{ Body length (cm) } & \multicolumn{2}{|c|}{ Weight (g) } \\
\hline & & Range & Average & Range & Average \\
\hline Agkistrodon saxatilis & 61 & $6-69$ & 58.8 & $34-126$ & 67.9 \\
\hline Dinodon rufozonatum & 80 & $81-119$ & 99.5 & $107-255$ & 172.8 \\
\hline Elaphe davidi & 50 & $63-105$ & 79.6 & $37-146$ & 74.5 \\
\hline Elaphe schrenckii & 20 & $150-182$ & 165.4 & $725-1,273$ & 894.0 \\
\hline
\end{tabular}

In the Republic of Korea, the third-stage larvae of $G$. spinigerum were detected in the abdominal muscle of a snake head, Channa argus (Kim, 1973), and the thirdstage larvae of G. nipponicum and G. hispidum were detected in the viscera of Chinese loaches (Sohn et al., 1993; Sohn and Lee, 1996). G. hispidum larvae were also detected in the pit-viper snake, Agkistrodon brevicaudus (Sohn and Lee, 1998). Thus, in the present study, we detected larval gnathostomes from the red banded odd-tooth snake, Dinodon rufozonatum rufozonatum, which had been smuggled from China and confiscated at Busan Customs. They were identified as the third-stage larvae of G. hispidum, on the basis of their morphological characteristics. The primary objective of the present study is to describe the detection and identification of larval G. hispidum in the snake, D. rufozonatum rufozonatum, smuggled from China.

\section{MATERIALS AND METHODS}

We obtained a substantial number of (more than 211) snakes, consisting of 4 species including the red banded odd-tooth snake, D. rufozonatum rufozonatum, from Busan Customs, in October 2002 (Table 1). The snakes had been smuggled from China and confiscated by a customs officer. A total of 211 snakes (Table 1) were examined in our laboratory. Their muscles and viscera were isolated and artificially digested with pepsin- $\mathrm{HCl}$ solution in an incubator at $36^{\circ} \mathrm{C}$. The digested material was washed with $0.85 \%$ saline and examined under a stereomicroscope.

Some of the worms collected were fixed in $10 \%$ formalin, cleared in alcohol-glycerin solution, mounted in glycerin-jelly, and observed under a light micro- scope. In order to observe the surface ultrastructure, some of the worms were washed several times in 0.2 $\mathrm{M}$ cacodylate buffer ( $\mathrm{pH}$ 7.2) and fixed in $2.5 \%$ glutaraldehyde at $4^{\circ} \mathrm{C}$. After 3 washings with this buffer, they were dehydrated through a graded alcohol series (50\%, 70\%, 80\%, 90\%, 95\%, and absolute alcohol), dried in a critical point dryer, coated with gold in the JFC-1100E ion sputtering device (JEOL, Tokyo, Japan), and observed using a scanning electron microscope (Philips XL-30S, Amsterdam, Netherlands) with an accelerating voltage of $20 \mathrm{kV}$.

\section{RESULTS}

\section{Recovery of gnathostome larvae in snakes}

A total of 205 larval gnathostomes, identified as G. hispidum (Fig. 1), were collected from 18 (22.5\%) D. rufozonatum rufozonatum. Only one larva of $G$. hispidum was detected in 1 (2.0\%) specimen of Elaphe davidi (Table 2).

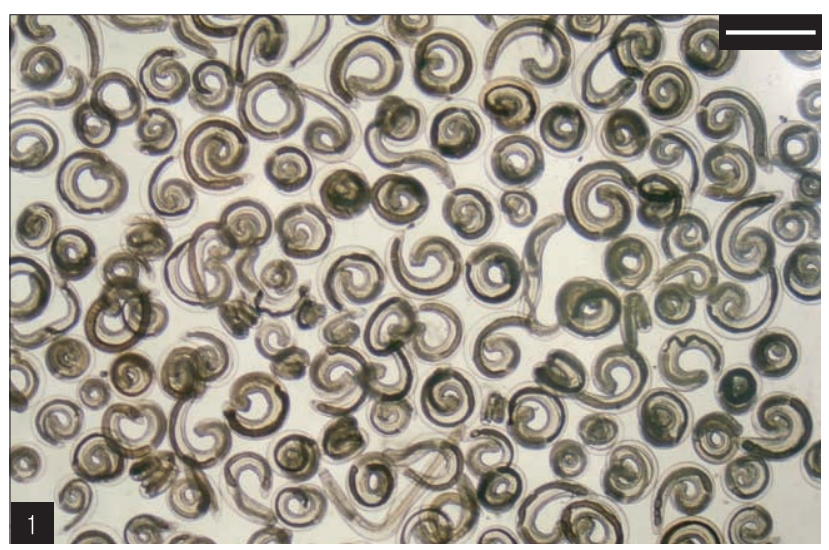

Fig. 1. Gnathostome larvae collected in the red banded odd-tooth snakes, D. rufozonatum rufozonatum, smuggled from China. Bar is $1 \mathrm{~mm}$. 
Table 2. Infection status of Gnathostoma hispidum larvae in 2 species of snakes from China

\begin{tabular}{lccrc}
\hline Species of snake & $\begin{array}{c}\text { No. of snakes } \\
\text { examined }\end{array}$ & $\begin{array}{c}\text { No. }(\%) \\
\text { of snakes infected }\end{array}$ & Total & Range \\
\hline D. rufozonatum & 80 & $18(22.5)$ & 205 & $1-110$ \\
E. davidi & 50 & $1(2.0)$ & 1 & 1.4 \\
\hline
\end{tabular}
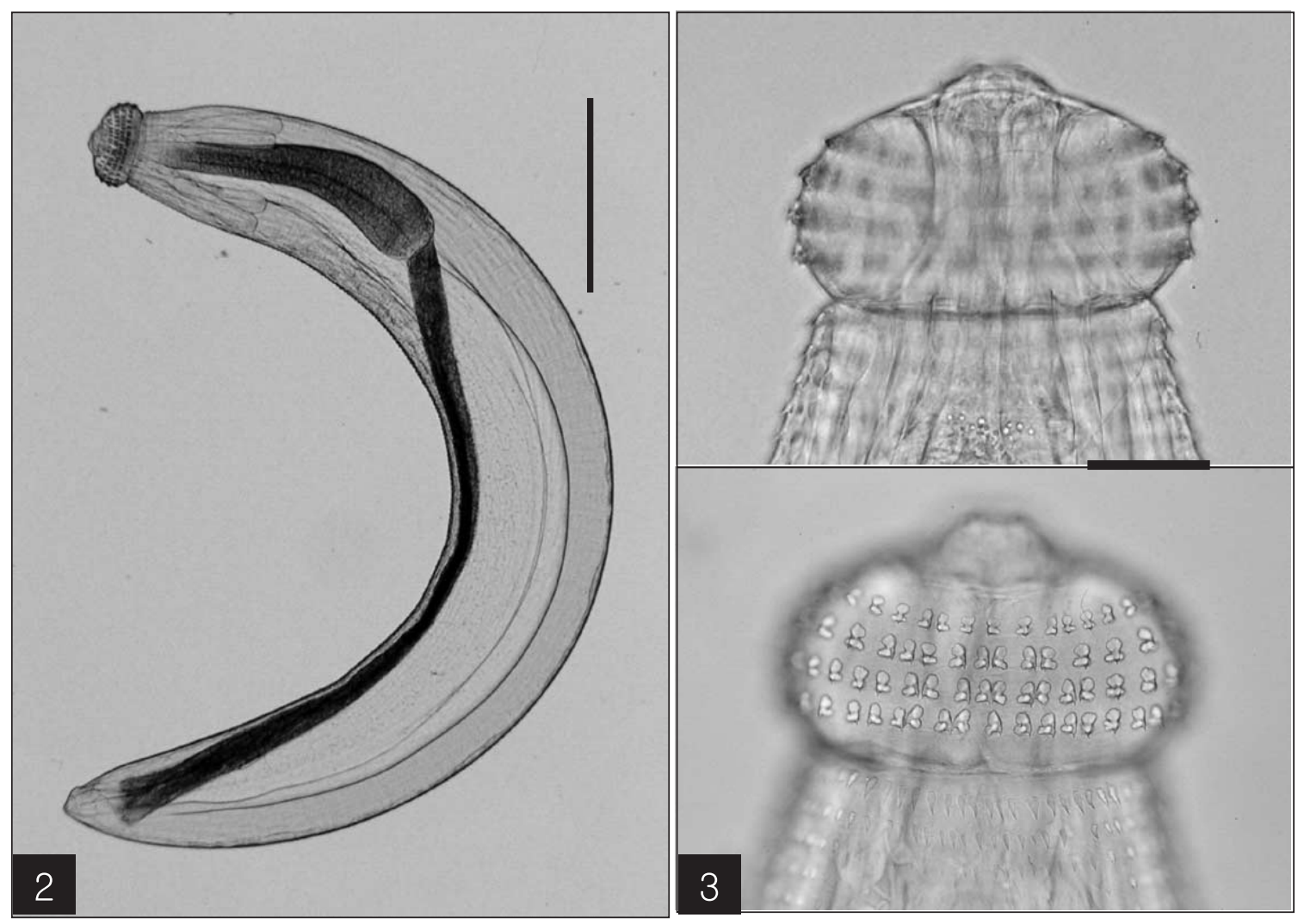

Fig. 2. The advanced third-stage larva of Gnathostoma hispidum recovered from the muscles of snakes. Bar is $300 \mu \mathrm{m}$. Fig. 3. The head bulb of the larva bearing 4 transverse rows of hooklets. Bar is $50 \mu \mathrm{m}$.

\section{Description of G. hispidum larvae from D. rufo- zonatum rufozonatum}

The entire body of the larvae was covered with approximately 220 transverse rows of minute spines, with an average size of $2.18 \times 0.29 \mathrm{~mm}$. A pair of lips protruded at the anterior end, followed by a muscular esophagus (0.67 $\mathrm{mm}$ in average) and brownish intestines, and the anus opened at the ventral side of the posterior end. Two pairs of cervical sacs $(0.31 \mathrm{~mm}$ in average) were clearly observed in the esophageal region (Fig. 2). The characteristic head bulb $(0.07 \mathrm{x}$ $0.17 \mathrm{~mm}$ in average size) was equipped with 4 rows of hooklets (Fig. 3). The average number of hooklets in the respective row was 38.6, 40.5, 41.5, and 43.7, counting in a posterior direction. The observed morphological features and measurements were consistent with those of G. hispidum reported by previous authors (Table 3).

\section{SEM findings of the larvae}

The larvae evidenced a characteristic head bulb, numerous transverse striations with cuticular spines, and an anus (Fig. 4). In the head bulb, the mouth had a pair of lateral lips of equal size. Each lip featured a couple of labial papillae and a small amphid located 
Table 3. Measurements of G. hispidum larvae from D. rufozonatum rufozonatum and comparison with previous reports (unit: $\mathrm{mm}$ )

\begin{tabular}{lccc}
\hline Organs & $\begin{array}{c}\text { Sohn and Lee } \\
(1996)^{\mathrm{a})}\end{array}$ & $\begin{array}{c}\text { Sohn and Lee } \\
\left.(1998)^{\mathrm{b}}\right)\end{array}$ & $\begin{array}{c}\text { Present study } \\
(2007)^{\mathrm{c}}\end{array}$ \\
\hline $\begin{array}{l}\text { Body length } \\
\quad \text { width }\end{array}$ & $2.24-3.08(2.66)$ & $1.73-2.53(2.23)$ & $1.63-2.63(2.18)$ \\
Esophagus & $0.31-0.38(0.35)$ & $0.29-0.39(0.34)$ & $0.22-0.35(0.29)$ \\
Cervical sac & $0.71-0.82(0.76)$ & $0.66-0.92(0.77)$ & $0.55-0.80(0.67)$ \\
Head bulb & $0.31-0.46(0.36)$ & $0.29-0.41(0.34)$ & $0.26-0.35(0.31)$ \\
$\quad$ length & & & \\
$\quad$ width & $0.09-0.12(0.10)$ & $0.07-0.10(0.08)$ & $0.05-0.08(0.07)$ \\
No. of hooklets on the head-bulb & $0.18-0.20(0.19)$ & $0.16-0.23(0.19)$ & $0.14-0.19(0.17)$ \\
$\quad$ & & & \\
1st row & & $33-40(36.8)$ & $36-42(38.6)$ \\
2nd row & $38-40(39.0)$ & $35-42(39.0)$ & $38-44(40.5)$ \\
$\quad$ 3rd row & $40-44(41.9)$ & $40-44(41.7)$ & $38-46(41.5)$ \\
$\quad$ 4th row & $42-46(43.9)$ & $42-47(44.3)$ & $38-48(43.7)$ \\
\hline
\end{tabular}

${ }^{a)}$ Data (range with average) from 10 larvae from experimental mice.

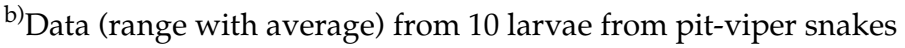

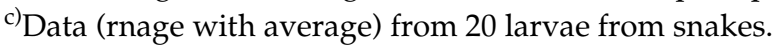
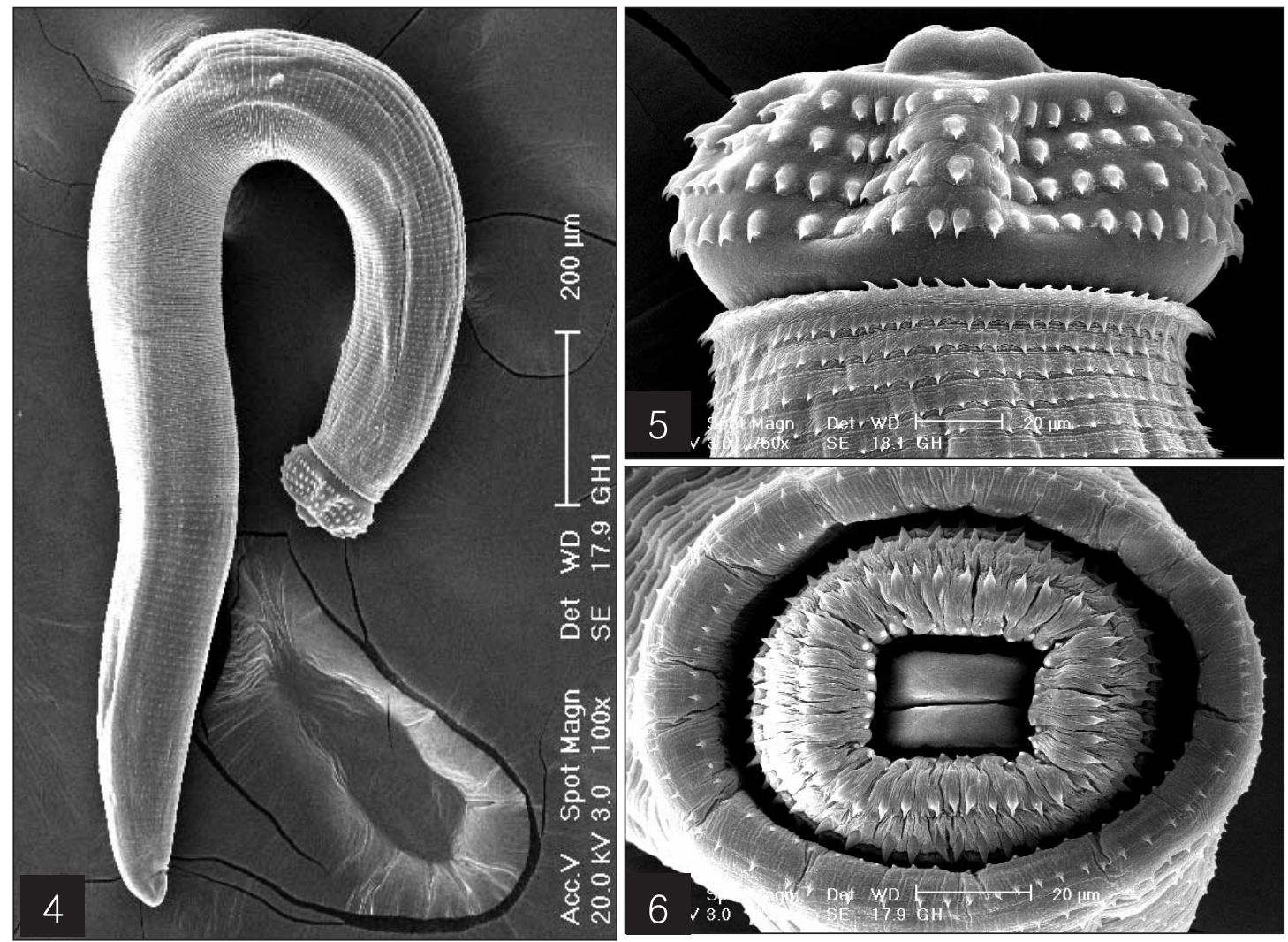

Figs. 4-11. Scanning electron microscopic (SEM) view of the advanced third-stage larvae of G. hispidum from the red banded odd-tooth snake, $D$. rufozonatum rufozonatum. Fig. 4 . Whole body showing a head bulb, numerous transverse striations with cuticular spines and an anus. Fig. 5. The head bulb of larva bearing 4 transverse rows of hooklets. Each hooklet with a sharp point somewhat curved posteriorly. Fig. 6. Frontal view of the head bulb, which is somewhat retractable into the body. 

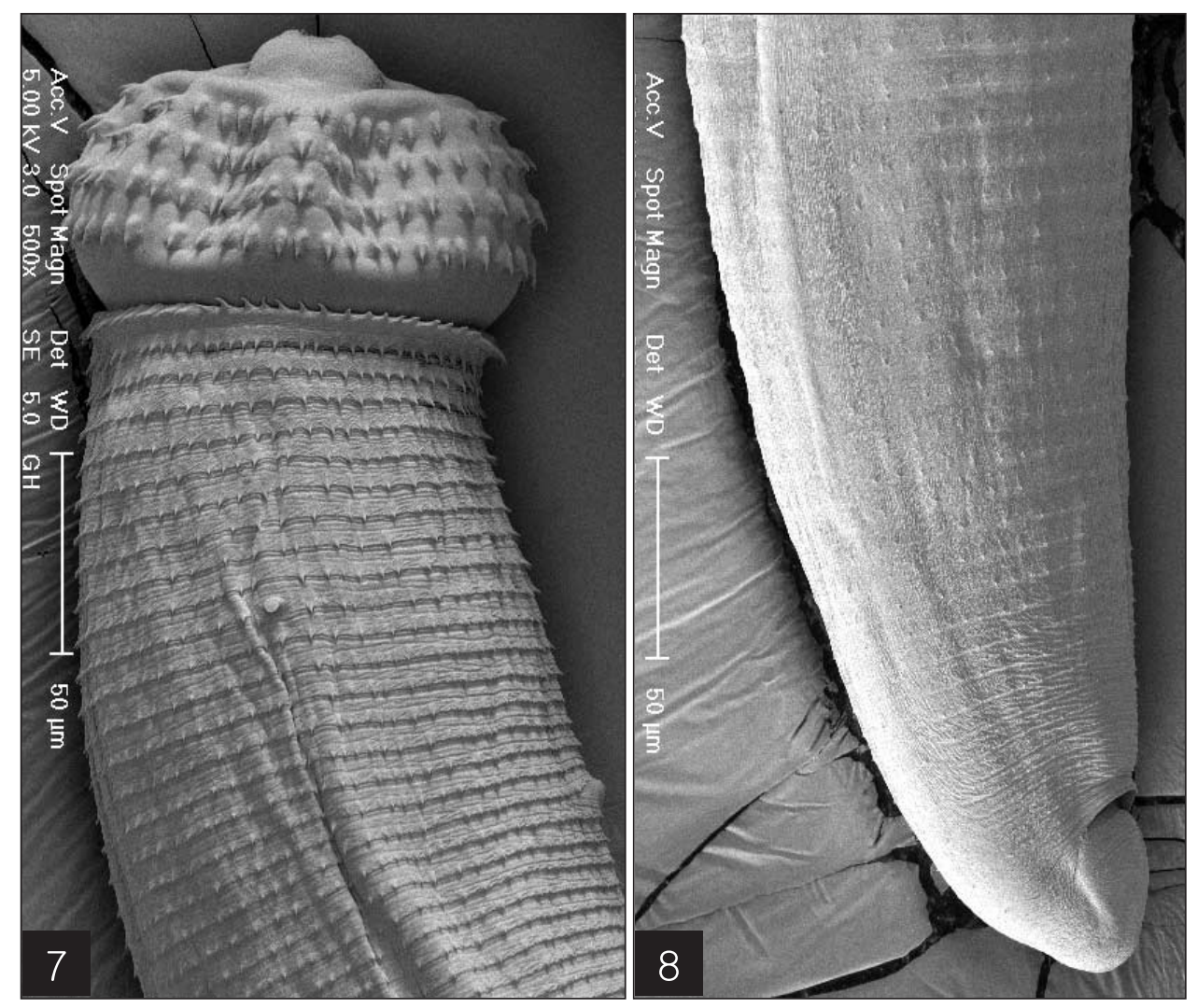

Fig. 7. Anterior part of a larva with a head bulb, numerous transverse striations with cuticular spines, a cervical papilla (arrow head) located between 10th and 11th transverse striations and a body papilla (arrow mark) between 19th and 20th transverse striations. Fig. 8. Posterior part of a larva with numerous transverse striations has smaller cuticular spines, and an anus.

between the two papillae. The hooklets located on the head bulb evidenced single-pointed, posteriorlycurved tips (Figs. 5 and 6). A cervical papilla was located between the 10th and 11th transverse striations, and a body papilla was located between the 19th and 20th transverse striations (Fig. 7). The anus was half-moon shaped, and opened at the ventral side of the posterior end (Fig. 8). The cuticular spines were larger and more densely distributed in the anterior area and gradually decreased in size and number, in a posterior direction. The body surface of the anterior part was very wrinkled and evidenced shape-pointed cuticular spines on the transverse striations. The surface of the middle part of the body evidenced transverse ridges and smaller cuticular spines on the transverse striations. The body surface of the posterior portion consisted of a smooth cuticle, the spines of which were distributed more sparsely on the transverse stri- ations (Figs. 9, 10 and 11).

\section{DISCUSSION}

G. hispidum is a relatively common nematode parasite that infects domestic and wild pigs in Asia and Europe. It is distributed widely from Southeast Asia to the Far East, including the Republic of Korea (Sohn and Lee, 1998). In the case of China, the prevalence of adult worms in domestic pigs has been reported by some Chinese investigators (Chen, 1936; Wang et al., 1976; Huang et al., 1986), and the infection status of larval worms was investigated in loaches imported from China by Japanese (Akahane and Mako, 1984; Koga et al., 1985) and Korean (Sohn and Lee, 1996) workers. However, few studies have been conducted regarding larval worm infections in the snake host. Therefore, this study appears to be the first to verify 

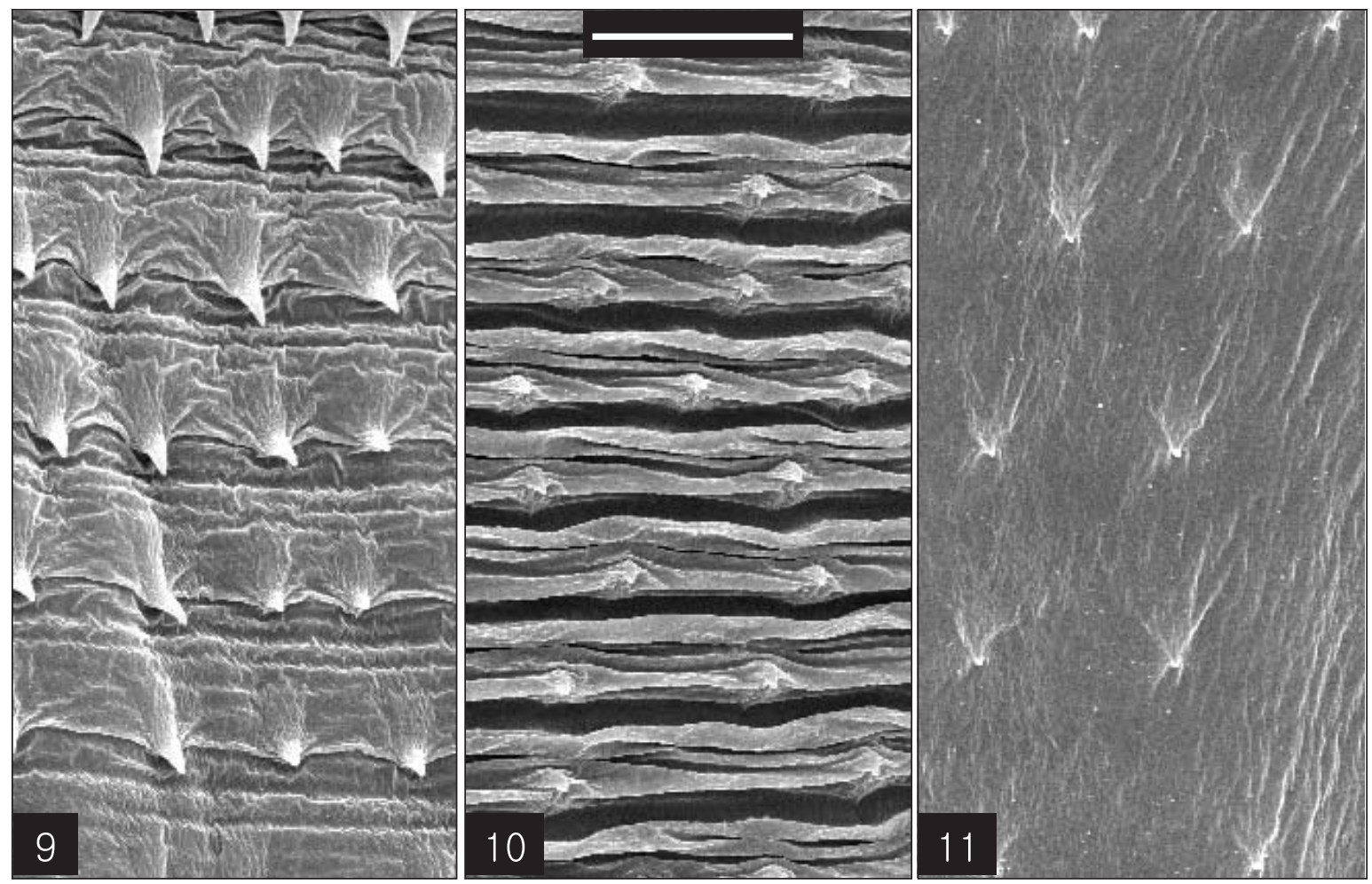

Fig. 9. Body surface of the anterior part consists of a highly wrinkled cuticle and has shape-pointed cuticular spines on the transverse striations. Fig. 10. Body surface of the middle part has transverse ridges and smaller cuticular spines on the transverse striations. Bar is $10 \mu \mathrm{m}$. Fig. 11. Body surface of the posterior part consists of smooth cuticle of which spines are more sparsely distributed on the transverse striations.

that the red banded odd-tooth snake, D. rufozonatum rufozonatum, plays a crucial role as a transport host for G. hispidum in China.

Several snake species have been reported as the transport or paratenic hosts of gnathostomes. G. spinigerum larvae were detected in the snakes, Python reticularis, Naja bungarus, and Naja tripudianus in India (Chandler, 1925), and from Natrix tigrina tigrina, Dinodon orientale, and Elaphe quadrivirgata in Japan (Yamaguti et al., 1956; Miyazaki, 1960). Larval Gnathostoma procyonis was detected in Agkistrodon piscivorus and Natrix sipendon confluens in the USA (Miyazaki and Ash, 1959). In the case of G. doloresi larvae, Japanese workers discovered the species in several species of snakes, namely, Trimeresurus elegans, Trimeresurus flavoviridis, Trimeresurus okinavensis, and Dinodon semicarinatus in Japan (Miyazaki and Kawashima, 1962; Tada et al., 1969; Toshioka, 1970; Mako and Akahane, 1985). Larval G. hispidum was detected only in the pit-viper, $A$. brevicaudus, in the Republic of Korea (Sohn and Lee, 1998). In the present study, D. rufozonatum rufozonatum from China was added to the list of snake intermediate hosts of $G$. hispidum.

The present study is the first to confirm that smuggled animals play the role as a transmission vehicle for various species of parasites. Thus far, many human cases of parasitic infections occurring in foreign countries have been reported in the Republic of Korea. However, no reports have yet been filed regarding the parasites in the smuggled animals, although parasites have been previously reported from imported food-animals (Sohn et al., 1993; Sohn and Lee, 1996). The primary parasites of snakes, including spargana, Neodiplostomum spp. mesocercariae, tetrathyridia and larval gnathostomes, are possible sources of human infections. Furthermore, they may represent a seed of zoonotic prevalence in the 
Table 4. Comparison of the number of hooklets on the head bulb in several species of larval Gnathostoma

\begin{tabular}{lcccc}
\hline Species & 1st row & 2nd row & 3rd row & 4th row \\
\hline G. nipponicum $^{\text {a) }}$ & $29-36(32)$ & $30-37(35)$ & $31-41(37)$ & - \\
G. doloresi $^{\text {a) }}$ & $34-42(38)$ & $35-43(40)$ & $34-39(36)$ & $33-41(37)$ \\
G. spinigerum $^{\text {a) }}$ & $40-47(43)$ & $37-49(45)$ & $42-52(47)$ & $48-58(52)$ \\
G. hispidum $^{\text {b) }}$ & $35-39(37)$ & $38-41(39)$ & $39-44(42)$ & $42-45(44)$ \\
The present study & $36-42(39)$ & $38-44(41)$ & $38-46(42)$ & $38-48(44)$ \\
\hline
\end{tabular}

a)From Miyazaki (1952).

${ }^{b)}$ From Sohn and Lee (1998).

Republic of Korea. Actually, it remains questionable as to whether surveillance regarding parasites in imported and/or smuggled food-animals has been conducted properly.

According to studies concerning the prevalence of adult gnathostomes in domestic pigs in China, Jiangxi Province is the most endemic area for G. hispidum (Chen, 1936; Wang et al., 1976; Huang et al., 1986). Jiangxi Province is located in the south-central region of China, is surrounded by land, and has some large freshwater lakes in the Nanchang vicinity, where the highest prevalence of G. hispidum has been reported. The peculiar natural conditions of Jiangxi Province, most notably the presence of freshwater lakes and the fact that pigs roam freely, may be instrumental in the maintenance of the complete life cycle of G. hispidum. On the other hand, Akahane and Mako (1984) have reported that the prevalence of larval G. hispidum in loaches from Nanking was higher than that of those observed in Peking and Tientsin. However, we were unable to determine the geographical origin of the snakes examined in the present study.

Miyazaki (1960) previously noted that the number, arrangement pattern, and shape of the hooklets on the head bulb are quite useful for the species identification of the genus Gnathostoma. The number and arrangement of hooklets on the head bulb of larval gnathostomes observed in the present study were compatible with those of G. hispidum as described by previous authors. However, they differed significantly from those of the 3 other species (Table 4) distributed throughout the Far East.

The SEM findings observed in the present study were not different from those reported by Sohn and
Lee (1998), with the exception of the location of cervical papillae. They mentioned that a cervical papilla is located between the 11th and 12th transverse striations, while in the present study, cervical papillae were conserved between the 10th and 11th transverse striations. The other features observed by SEM, including the 2 lips and labial papillae, the shape and arrangement of the hooklets on the head-bulb, and the distribution of transverse striations and cuticular spines, were consistent with the observations reported in previous studies (Kondo et al., 1984; Sohn and Lee, 1998).

\section{REFERENCES}

Akahane H, Mako T (1984) Infection patterns of Gnathostoma hispidum in loaches imported from mainland China. Jpn J Parasitol 33: 509-513 (in Japanese).

Ando K, Tanaka H, Taniguchi Y, Shimizu M, Kondo K (1988) Two human cases of gnathostomiasis and discovery of a second intermediate host of Gnathostoma nipponicum in Japan. J Parasitol 74: 623-627.

Araki T (1986) Gnathomiasis-parasitic diseases caused by eating raw loaches. Kansen Ensyou Meneki (Infection, Inflammation and Immunology) 16: 110-111 (in Japanese).

Chandler AC (1925) A contribution to the life history of gnathostomes. Parasitology 17: 237-244.

Chen HT (1936) Parasites in slaughter houses in Canton. Part 1. Helminths of Kwangtung hogs. Lingnan Sci J 15: 31-44.

Demitsu T, Aizawa H (1985) Gnathostomiasis cutis. Rinshohifuka 39: 255-260 (in Japanese).

Huang WC, Xia BF, Koga M, Ishii Y (1986) A survey on Gnathostoma hispidum Fedtschenko, 1872 in Jiangxi, People's Republic of China. Jpn J Parasitol 35: 223-227.

Kim YK (1973) A study on Gnathostoma (1) An investigation 
into the geographical distribution of larvae on the second and third stage in Gyeongsang Nam do. Bull Pusan Nat Univ (Natur Sci) 15: 111-116 (in Korean).

Kondo K, Akao N, Takakura Y, Ohnishi Y, Konishi Y, Yoshimura H (1984) Scanning electron microscopy (SEM) of larvae and adult worms of Gnathostoma hispidum. Jpn J Parasitol 33: 577-586 (in Japanese).

Mako T, Akahane H (1985) On the larval Gnathostoma doloresi found in a snake, Dinodon semicarinatus from AmamiOshima Is., Japan. Jpn J Parasitol 34: 493-499.

Miyazaki I (1952) On the second stage larvae of three species of Gnathostoma occurring in Japan (Nematoda: Gnathostomidae). Acta Med 22: 1433-1441 (in Japanese).

Miyazaki I (1960) On the genus Gnathostoma and human gnathostomiasis, with special reference to Japan. Exp Parasitol 9: 338-370.

Miyazaki I (1991) An Illustrated Book of Helminthic Zoonoses. pp 368-409, International Medical Foundation of Japan, Tyoko, Japan.

Miyazaki I, Ash LR (1959) On gnathostome larvae found from snakes in New Orleans, USA. Jap J Parasitol 8: 351352.

Miyazaki I, Kawashima K (1962) On the larval Gnathostoma doloresi Tubangui found in a snake from Ishigaki-jima, the Ryuku Island (Nematoda: Gnathostomidae). Kyushu J Med Sci 13: 165-169.

Morishita K (1924) A pig nematode, Gnathostoma hispidum Fedtschenko, as a human parasite. Ann Trop Med Parasitol 18: 23-26.

Morita H, Segawa T, Nishiyama T (1984) Gnathostoma cases caused by imported loaches. J Nara Med Ass 35: 607-619 (in Japanese).

Nawa Y, Imai J, Ogata K, Otsuka K (1989) The first record of a confirmed human case of Gnathostoma doloresi infection. J Parasitol 75: 166-169.

Sohn WM, Kho WG, Lee SH (1993) Larval Gnathostoma nipponicum found in the imported Chinese loaches. Korean $J$ Parasitol 31: 347-352.

Sohn WM, Lee SH (1996) Identification of larval Gnathostoma obtained from imported Chinese loaches. Korean J Parasitol 34: 161-167.

Sohn WM, Lee SH (1998) The first discovery of larval Gnathostoma hispidum (Nematoda: Gnathostomidae) from a snake host, Agkistrodon brevicaudus. Korean J Parasitol 36: 81-89.

Tada I, Sato A, Nagano K (1969) On the larval Gnathostoma doloresi found in snakes, Trimeresurus flavoviridis flavoviridis, from Amamii-oshima Is., Kagoshima, Japan. Jap J Parasitol 18: 289-293.

Toshioka S (1970) On the larval Gnathostoma doloresi Tubangui found in the himehabu, Trimeresurus okinavensis, from Amami Islands, Kagoshima Prefecture, Japan. Snake 2: 57-58.

Wang P, Sun Y, Zhao Y (1976) On the development of Gnathostoma hispidum in the intermediate host with special reference to its transmission route in pigs. Acta Zool Sinica 22: 45-52.

Yamaguti T, Yamamoto Y, Ijima Y, Sakamoto Y, Irie T, Yanagihara T, Murakami K, Horie N, Tsuno K (1956) Studies on Gnathostoma in Shikoku. Shikoku Acta Med 9: 316-326. 